\title{
Refugees, Migration and Global Governance. Negotiating the Global Compacts. Elisabeth G. Ferris y Katharina M. Donato. London: Routledge, 2020
}

\author{
Lorenzo Cachón Rodríguez \\ Universidad Complutense de Madrid, España \\ lcachonr@ucm.es
}

El 19 de septiembre de 2016 la Asamblea General de Naciones Unidas aprobó la "Declaración de Nueva York para los refugiados y los migrantes". Esa declaración pasó inadvertida no solo para el gran público, sino para muchos académicos que trabajan en el campo de las migraciones internacionales. Tenía un precedente el objetivo 10.7 de la "Agenda 2030 para el desarrollo sostenible", aprobada en el mismo foro el año anterior. En él se planteaba la necesidad de "Facilitar la migración y la movilidad ordenadas, seguras, regulares y responsables de las personas, incluso mediante la aplicación de políticas migratorias planificadas y bien gestionadas". Dos años después de la Declaración de Nueva York, en diciembre de 2018, Naciones Unidas, con el apoyo de la mayoría de los países del mundo, aprobó el Pacto Mundial sobre Refugiados (PMR) y el Pacto Mundial para la Migración Segura, Ordenada y Regular (PMM). Ambos pactos, pero especialmente el PMM, suponen un logro histórico hacia una gobernanza multilateral de las migraciones internacionales. No hay que olvidar el momento y el contexto en que se han pergeñado, negociado y aprobado estos pactos: a la tragedia de los refugiados causada por la brutal guerra de Siria, hay que unir el desgarrón de las costuras de la Unión Europea por la mal llamada crisis de los refugiados y la creciente llegada al escenario internacional de dirigentes xenófobos capitaneados por Trump, que llegó a la presidencia de Estados Unidos tres meses después de la Declaración de Nueva York. El momento (de los desplazamientos de refugiados y de migrantes) hacía estos pactos necesarios, el contexto (político) los hacía (casi) imposibles. Y, sin embargo, Naciones Unidas adoptó esos pactos sobre refugiados y migraciones que ponen las bases para una nueva gobernanza de los desplazamientos de personas en el mundo.

Refugees, Migration and Global Governance. Negotiating the Global Compacts es un libro que ayuda a comprender los pactos, su proceso de formulación y los desafios que han de abordar a partir de ahora. Sus autoras son dos profesoras estadounidenses de referencia de la Universidad de Georgetown en Washington D.C. Elisabeth Ferris es profesora de investigación en el Institute of Study of International Migration y ha trabajado en cuestiones ligadas a los refugiados en la Secretaría General de Naciones Unidas; Katharina Donato es profesora de Migraciones Internacionales y directora del Institute of Study of International Migration.

Las autoras hacen un análisis de los pactos desde la lógica "realista" de los regímenes de gobernanza global donde los principios, normas y procesos de decisión vienen a reflejar los intereses de los estados más poderosos en el sistema (frente a una posible visión "constructivista" en la dicotomía de regímenes de gobernanza global que presentó S. Krasner, en la que primarían las expectativas de las partes). El "régimen internacional de refugiados" y el "régimen internacional de migraciones" han nacido, sobre todo, en respuesta a los intereses de estados poderosos en el orden internacional, especialmente de Estados Unidos y países europeos. Pero los procesos de negociación de los dos pactos mundiales "indican 
- señalan las autoras - que estaba en juego una convergencia de intereses más matizada entre los países del norte y del sur. Los pactos mundiales no solo reflejan el interés de los países desarrollados poderosos; las preocupaciones de los países en desarrollo por un reparto de responsabilidades más efectivo y por más acciones para defender los derechos de los migrantes se manifiestan claramente en los documentos finales".

Tras aportar un breve y claro resumen de las tendencias recientes en el campo de las migraciones y de los refugiados, analizan el contexto político en que se llegó a la Declaración de Nueva York y que resumen como "xenofobia creciente" en la cual "el tema de la inmigración se ha convertido en un tema político candente, el tema político más candente, en los Estados Unidos y en Europa, y es quizás el desafío central para el orden mundial liberal. La inmigración ha sido retratada como un desafio existencial a la pieza clave del sistema internacional, la soberanía nacional". Ese fue el contexto en el que, sin embargo, se aprobó la Declaración de Nueva York de 2016 y se puso en marcha la negociación de los dos pactos.

Pero ¿qué desafíos afrontaban los regímenes internacionales de refugiados y de la migración internacional en ese momento (y en el momento presente)? La situación era (y es) muy distinta tanto por el marco normativo en que se basan como por los actores que participan en cada uno de estos regímenes. El régimen de refugiados, cuyo origen tras la Segunda Guerra Mundial se explica muy bien en el libro, tiene como pieza fundamental la Convención de refugiados de Ginebra de 1951 y el Protocolo de 1967. La Convención establece una serie de derechos de los refugiados, especialmente el de "no devolución" (non-refoulement) a su país de origen. 148 países han ratificado esta Convención. Además, algunas áreas como la África, América Latina o la Unión Europea han complementado la Convención. El actor internacional el este campo es ACNUR (Oficina del Alto Comisionado de las Naciones Unidas para los Refugiados). Pero el régimen internacional de refugiados tiene una serie de desafios que Ferris y Donato sintetizan en seis aspectos: 1 ) el hecho de que los actores humanitarios no pueden responsabilizar a los gobiernos cuando provocan desplazamientos de refugiados y la dificultad de resolver conflictos por parte de la ONU; 2) la ausencia de cualquier monitoreo del cumplimiento por parte de los gobiernos de sus obligaciones legales bajo la Convención de $1951 ; 3$ ) la ausencia de un mecanismo robusto para compartir responsabilidades por los refugiados (que tiene que ver tanto con la financiación como con el reasentamiento de refugiados) (¿es necesario recordar aquí el rotundo fracaso de la UE en el reparto de los refugiados que llegaron en 2015?); 4) la necesidad de mayor coordinación entre los actores de desarrollo y los actores humanitarios; 5) la ausencia de un marco para el apoyo a los personas desplazadas dentro de su propio país (IDP, por sus siglas en inglés), y 6) la necesidad de reforzar ACNUR.

Tanto el marco normativo como los actores relevantes del régimen internacional de las migraciones son muy diferentes. A pesar de dos Convenios sobre migraciones laborales aprobados por la Organización Internacional del Trabajo (OIT), a pesar de la idea que se barajó a mediados del siglo pasado de hacer que la OIT actuara como agencia de Naciones Unidas en el campo de la migraciones internacionales, y a pesar de la adopción por parte de la Asamblea General de Naciones Unidas de la Convención internacional sobre la protección de los derechos de todos los trabajadores migrantes y de sus familias en 1990, puede decirse que no hay (hasta la aprobación del PMM) un marco normativo para la gobernanza de las migraciones internacionales. Tanto los convenios de la OIT (el 97 y el 143) como la Convención de Naciones Unidas de 1990 tienen muy pocos estados signatarios como para que puedan considerarse normas efectivas a nivel mundial. El régimen internacional de las migraciones tampoco ha tenido, como sí ocurre con el de refugiados, una agencia de referencia. Varias agencias de Naciones Unidas relacionadas sobre todo con derechos humanos han abordado competencias dispersas sobre diferentes ámbitos ligados a las migraciones internacionales. Porque esa agencia de referencia no ha sido la Organización Internacional de la Migraciones (OIM), una organización intergubernamental creada en 1989 a partir del 
Comité Intergubernamental Provisional para los movimientos de los Migrantes desde Europa (PICMME, por sus siglas en inglés) que se había puesto en marcha en 1951. Como sintetizan las autoras, "A diferencia del régimen internacional de refugiados, el sistema de migración global carecía en el siglo XX de un marco normativo fuerte y centralizado. El principal actor organizacional, OIM, carecía de un mandato de protección, lo que comprometía su posición".

Pero en 2014-2015 estos dos regímenes se van a ver confrontados a crisis comunes que los desafian a los dos a la vez: refugiados y migrantes de Centroamérica llegan a la frontera sur de Estados Unidos; refugiados sirios y migrantes de otras nacionalidades llegan a las fronteras de la Unión Europea. Todos viven peligrosas experiencias del viaje, a veces trágicas, todos usan las mismas vías y a veces se apoyan en los mismos traficantes. En noviembre de 2015, la Asamblea General aborda la cuestión en dos ocasiones. Los títulos de sus convocatorias son muy significativos: "Conciencia global sobre la tragedia de los migrantes irregulares en la cuenca mediterránea con énfasis en los solicitantes de asilo sirios" y "Formas de avanzar en una respuesta integral a la crisis global humanitaria y de refugiados".

Refugees, Migration and Global Governance, describe de modo detallado el complejo proceso de elaboración del PMR y del PMM, con la Declaración de Nueva York de 2016 como punto formal de inicio del proceso. Es importante señalar que, desde el principio, ambos pactos de conciben como no vinculantes jurídicamente (respetando la soberanía de los estados), pero inspirados por el principio de cooperación internacional.

Los dos pactos son muy diferentes en objetivos y alcance, y reflejan el distinto momento de desarrollo de los regímenes internacionales de refugiados y de las migraciones. El PMR es un documento pragmático, desarrollado en un momento particular en el tiempo, que ha prestado atención al reparto de responsabilidades y a la incorporación de un conjunto de actores directos. Por su parte, el PMM presenta por primera vez, un nuevo marco general para abordar la migración con un doble énfasis: proteger los derechos humanos de los migrantes, y apoyar a los gobiernos en la gestión de sus fronteras. Tienen razón Ferris y Donato al señalar que el PMR es "es bastante conservador al tratar de preservar el marco existente, y hay pocas novedades en él (...) los dos logros más importantes son su afirmación de la necesidad de compartir la responsabilidad y su reconocimiento de la necesidad de los comprometer a muchos actores, no solo a ACNUR (...) En conclusión, el PMR refuerza en gran medida el statu quo (que dado el contexto antiinmigrante y antirefugiado en el que se negoció es probablemente lo mejor que se podría esperar)".

La valoración del PMM debe ser muy distinta. El PMM contiene 23 objetivos y en ellos hay hasta 187 acciones que recogen, con amplitud y profundidad, una amplia panoplia de prácticamente todas las cuestiones relevantes para una gestión de las migraciones internacionales de modo más seguro, ordenado y regular. Como Cachón y Aysa han señalado, "el PMM ni es un tratado ( $y$, por tanto, no es de obligado cumplimiento), ni presenta un conjunto de reglas (normas jurídicas) que haya que seguir o implementar en el derecho interno de los países, ni contiene objetivos específicos que los estados deban alcanzar en una fecha determinada, ni aporta compromisos presupuestarios. El Pacto de autodefine como 'un marco de cooperación no vinculante jurídicamente'. (Pero) lo que sí hay en el Pacto son claras guías para la acción (política y social) en la gestión de las migraciones internacionales; es decir, claros compromisos políticos (y morales) asumidos por los Estados miembros de Naciones Unidas".

Las autoras recogen algunas limitaciones del PMM que han sido puestas de relieve en la literatura académica: que no aborda de modo suficiente la cuestión de la migración irregular (aunque esta crítica es matizable porque el PMM hace numerosas referencias a la cuestión), que la debilidad con el que se apuntan vías de migración legal (dificil por la diversidad de sistemas de regulación nacionales existentes), la falta de contundencia respecto a la detención de menores migrantes, o la ya señalada falta de mecanismos de cumplimiento. 
Otras críticas, que han impedido que el PMM tenga un mayor apoyo, vienen de dirigentes con marcado cariz antiinmigración que critican que el PMM ponga tanto el acento en los beneficios de las migraciones y en los derechos humanos de los migrantes y que señalan (sin fundamento) que el PMM atenta contra la soberanía de los estados en su capacidad para (intentar) regular las migraciones que llegan a sus fronteras.

Hay, además, dos importantes cuestiones de la movilidad de las personas que no han sido abordadas en estos dos pactos: es la problemática ligada a personas que no son refugiados pero que tienen necesidad de protección, y "el gran número de personas desplazadas dentro de las fronteras nacionales y la posibilidad de que esas personas soliciten protección y asistencia en otros países". Esta referencia a las IDP que entrecomillamos está en la Declaración de Nueva York y, sin embargo, ninguno de los dos pactos ha abordado la cuestión.

Al final de libro Ferris y Donato hacen un balance de los pactos y señalan el camino a seguir: "La adopción de los dos pactos mundiales durante una época de xenofobia desenfrenada fue una gran victoria para el multiculturalismo. Aunque estén lejos de ser perfectos, los pactos ofrecen oportunidades para una mayor acción colectiva sobre quizás el mayor desafio de nuestro tiempo: el movimiento de personas a gran escala. Hubiera sido un duro golpe para el multiculturalismo y para la ONU si no hubiera logrado adoptar estos dos pactos. Ahora que existen, queda por ver si conducirán a un reparto más eficaz de responsabilidades en la cuestión de los refugiados y a una migración menos irregular y más segura, ordenada y regular. El potencial ciertamente existe, pero los estados, las organizaciones internacionales, las ONG y otras partes interesadas. tendrán que mostrar la misma obstinada dedicación a la implementación de los pactos que la que tuvieron durante los dos años que llevó su adopción. Si lo hacen, los pactos globales habrán contribuido a un mundo mejor".

El libro de Elisabeth Ferris y de Katharine Donato nos permite adentrarnos en el contexto en que se produjo la Declaración de Nueva York y el proceso de negociación de los pactos mundiales sobre refugiados y sobre migraciones. Y proporciona una excelente introducción a la compleja dinámica de la gobernanza global de los desplazamientos de personas en el siglo XXI y los desafios que plantea para la defensa de los derechos humanos de refugiados y migrantes. A la vez que pone de manifiesto el impresionante paso adelante que es el PMM, al adoptar por primera vez un marco multilateral sobre el que construir la cooperación internacional en la gobernanza de la migración.

El "tema de nuestro tiempo", que diría Ortega y Gasset, es la pandemia producida por el covid-19. Y cabe preguntarse si estos pactos de Naciones Unidas, y especialmente el PMM, son adecuados para la gestión de las migraciones en estos tiempos (¿nuevos?) de las migraciones internacionales. La respuesta es que hoy, sin duda, los pactos marcan el camino que debería seguirse en la gobernanza de las migraciones. Porque si algo ha puesto de manifiesto esta pandemia es la urgencia de garantizar los derechos de los migrantes y refugiados, la necesidad de tienen las sociedades receptoras de inmigrantes en muy distintas áreas, la conveniencia de regularizar a inmigrantes en situación irregular, o los beneficios de las migraciones para todos si se llevan a cabo de modo seguro, ordenado y regular. 